\title{
DETERMINANTAL INEQUALITIES FOR THE PSI FUNCTION
}

\author{
BiAGIO PALUMBO
}

Abstract. Some inequalities concerning determinants which involve the psi function (logarithmic derivative of the gamma function) are established.

Mathematics subject classification (1991): 33B15.

Key words and phrases: psi function, Hankel determinantal inequalities, convexity, log-convexity.

\section{REFERENCES}

[1] M. Abramowitz, I. A. Stegun, Handbook of mathematical functions with formulas, graphs, and mathematical tables, National Bureau of Standard Applied Mathematics Series 55, June 1964.

[2] C. Giordano, B. Palumbo, J. PeČArić, Remarks on the Hankel determinantal inequalities, Rendiconti del Circolo Matematico di Palermo, Serie II, Tomo XLVI (1997), 279-286.

[3] D. V. WIDDER, The Laplace transform, Princenton Univ. Press, Princeton, 1941. 